ARTICLE

\title{
3,3-Difluoroallyl ammonium salts: highly versatile, stable and selective gem-difluoroallylation reagents
}

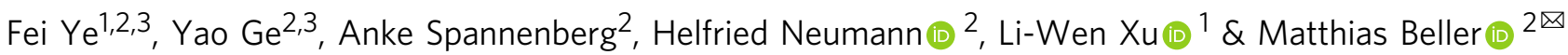

The selective synthesis of fluorinated organic molecules continues to be of major importance for the development of bioactive compounds (agrochemicals and pharmaceuticals) as well as unique materials. Among the established synthetic toolbox for incorporation of fluorinecontaining units, efficient and general reagents for introducing $-\mathrm{CF}_{2}$ - groups have been largely neglected. Here, we present the synthesis of 3,3-difluoropropen-1-yl ammonium salts (DFPAs) as stable, and scalable gem-difluoromethylation reagents, which allow for the direct reaction with a wide range of fascinating nucleophiles. DFPAs smoothly react with $\mathrm{N}-, \mathrm{O}-, \mathrm{S}-$, $\mathrm{Se}-$, and $\mathrm{C}$-nucleophiles under mild conditions without necessity of metal catalysts with exclusive regioselectivity. In this way, the presented reagents also permit the straightforward preparation of many analogues of existing pharmaceuticals.

\footnotetext{
${ }^{1}$ Key Laboratory of Organosilicon Chemistry and Material Technology of Ministry of Education, and Key Laboratory of Organosilicon Material Technology of Zhejiang Province, Hangzhou Normal University, No. 2318, Yuhangtang Road, Hangzhou 311121, PR China. ${ }^{2}$ Leibniz-Institute for Catalysis, Albert-Einstein-Str. 29a, Rostock 18059, Germany. ${ }^{3}$ These authors contributed equally: Fei Ye, Yao Ge. ${ }^{凶}$ email: matthias.beller@catalysis.de
} 
$\mathrm{n}$ general, the substitution of $\mathrm{C}-\mathrm{H}$ bonds by $\mathrm{C}-\mathrm{F}$ bonds in organic compounds leads to significant changes in their physical, chemical, and biological behavior. More specifically, properties such as solubility, metabolic stability, hydrogenbonding ability, lipophilicity, and chemical reactivity are strongly influenced by the incorporation of fluorine atoms ${ }^{1-4}$. Hence, an increasing number of products of the pharmaceutical and agrochemical industries as well as material sciences ${ }^{5}$ contain fluorine atoms as a crucial part ${ }^{6}$. Indeed, nearly $20 \%$ of the top 200 drugs in 2016 belong to this class of compounds ${ }^{7}$. Due to the dynamic development in this area more than $40 \%$ (45\% and $41 \%$ ) of FDA-approved drugs in $2018^{8}$, and $2019^{9}$ are fluorinecontaining. Even more pronounced, nearly $60 \%$ of the active ingredients for the agrochemical industry are fluorinated compounds. Not surprisingly, the incorporation of fluorinecontaining groups has become one of the most important synthetic strategies for the design of new drugs and agrochemicals. Consequently, enormous efforts took place in academia and industry to develop such transformations ${ }^{10}$ (Fig. 1a), and many prominent fluoroalkylating agents containing $\mathrm{CF}_{3}$ or related groups were successfully introduced in the past years ${ }^{11-15}$. A selection of privileged reagents is shown in Fig. $1 \mathrm{~b}$.

In contrast to $-\mathrm{CH}_{2} \mathrm{~F}$ or $-\mathrm{CF}_{3}$ substituents, $-\mathrm{CF}_{2}-\mathrm{R}$ containing bioactive compounds are significantly less explored and comparably few marketed therapeutic agents exist yet (for some examples see Fig. 1c) ${ }^{16-23}$. So far, the most common route for their synthesis makes use of the fluorination of a pre-existing functional group using for example DAST or Deoxfluor ${ }^{24-26}$. Apart from the hazardous nature of these reagents, this approach is also limited with respect to functional group compatibility.

In our opinion, the restricted availability of general and selective synthetic methodologies clearly impeded the development of versatile building blocks with functionalized difluoromethyl units. As an alternative strategy, the direct introduction of difluoroalkyl groups forming $\mathrm{X}-\mathrm{CF}_{2}-\mathrm{R}$ bonds $(\mathrm{X}=\mathrm{C}, \mathrm{O}, \mathrm{N}$, $\mathrm{S}$, etc.; $\mathrm{R}=\mathrm{C})$ could solve this problem ${ }^{27-33}$. Especially, using gem-difluoroallyl moieties (a $-\mathrm{CF}_{2}-$ group neighboring to an alkene unit) offers attractive possibilities because of the wide variety of subsequent functionalizations and its occurrence in existing pharmaceuticals (see also Fig. 1c) ${ }^{16-20}$. Unfortunately, so far only a few methodologies for the direct intermolecular preparation of gem-difluoroallylic products are $\mathrm{known}^{34-46}$. This can be explained by the lack of suitable reagents like 3,3-difluoroallyl-X compounds ${ }^{47,48}$. Thus, 3-bromo-3,3difluoropropene (BDFP) has become the most popular surrogate for such transformations ${ }^{34-36,47}$, which has been applied exemplarily to construct difluoroallylated alcohols via metal-halogen exchange reactions (Fig. 1d, left) ${ }^{47-50}$. In addition, Tsuji-Trost allylations of BDFP and related substrates were also disclosed (Fig. 1d, right) ${ }^{34-38}$. More specifically, the groups of Zhang ${ }^{34}$, Ichikawa ${ }^{35}$, and most recently Cogwell ${ }^{36}$, reported interesting Pd-catalyzed gem-difluoroallylation of organoboranes, halophenols, and anilines, respectively.

Nevertheless, the use of BDFP has limitations due to its physical properties, e.g. volatility (b.p.: $41-42^{\circ} \mathrm{C}$ ) and substrate scope. In addition, the regioselective synthesis of the desired gemdifluoroallylated products requires the aid of stoichiometric amounts of metals or precious catalysts. In conclusion, to date, a general approach that meets the criteria of both broad reaction scope and high selectivity for gem-difluoroallylation reactions remains elusive.

As a solution, herein we describe the development of a family of easily available and bench-stable gem-difluorinated allyl ammonium salts (DFAAs), which allow exclusive $\gamma$-regioselective gem-difluoroallylation of $\mathrm{O}_{-}, \mathrm{N}-, \mathrm{S}-$, $\mathrm{Se}$-, and $\mathrm{C}$-nucleophiles (Fig. 1e). The resulting products, featuring a synthetically highly valuable $\mathrm{Nu}-\mathrm{CF}_{2} \mathrm{CH}=\mathrm{CH}_{2}$ unit, allow for the straightforward synthesis of diverse organofluorine compound libraries that offer numerous possibilities to enlarge the chemical space in the development of bioactive molecules.

\section{Results and discussion}

Although quaternary allyl ammonium salts are known for more than a century ${ }^{51}$, they received surprisingly little attention ${ }^{52-55}$. While investigating palladium-catalyzed cascade processes for the synthesis of spiro-fused heterocycles ${ }^{56}$, recently we noticed the utility and advantages of this class of compounds compared to other allylic electrophiles such acetates, halides, and so on. Inspired by this work and our interest in organofluorine building blocks ${ }^{56-61}$, we became interested in the synthesis and applications of DFAAs. Surprisingly, the parent 3,3-difluoropropen-1-yl ammonium salts (DFPAs) have not been described before.

Starting from 3,3,3-trifluoropropene, which is a commercial raw material, which is used for the preparation of a variety of products (e.g. in cosmetics, chemical manufacturing, etc.), basemediated amination with piperidine provided $\gamma, \gamma$-difluoroallyl piperidine smoothly as a colorless oil. Subsequent selective $N$ methylation $^{38}$, gave the desired 3,3-difluoropropen-1-yl ammonium salt 1a as a crystalline white powder without the need for chromatography or other tedious purifications in $56 \%$ overall yield. Following this two-step protocol other $\gamma, \gamma$-fluoro-substituted derivatives $\mathbf{1 b} \mathbf{b} \mathbf{- 1 e}$ can be obtained on gram-scale in a straightforward manner (Fig. 2a). Notably, all resulting products can be conveniently handled and are air-stable for months.

Having a small representative selection of fluorinated allyl ammonium salts in hand, we were interested to investigate their general reactivity. Here, we were especially interested in allylic substitution reactions with oxygen-derived or nitrogenderived nucleophiles because the resulting structural motifs $\mathrm{RCF}_{2}-\mathrm{O}, \mathrm{RCF}_{2}-\mathrm{N}$ are not easily accessible by other synthetic means. Thus, the model reaction of $\gamma, \gamma$-difluoroallyl ammonium salt 1a with 4 -phenyl phenol 2 was performed in the presence of a palladium catalyst under typical Tsuji-Trost conditions (toluene, $80^{\circ} \mathrm{C}, \mathrm{PdBr}_{2}, n$-butyl-diadamantylphosphine, cesium carbonate) ${ }^{62}$. To our delight, the desired difluoroallylic aryl ether product 3 is obtained in $92 \%$ yield and high selectivity (>99/1\%; Fig. 2 b, entry 1 ). Interestingly, performing a control experiment under identical conditions without the palladium catalyst revealed similar product yields ( $87 \%$ yield; Fig. 2b, entry 2), which can be explained by intrinsic reactivity for direct $\mathrm{S}_{\mathrm{N}} 2^{\prime}$ substitution in the presence of a base. Notably, even without any precious metal catalyst present, exclusive $\gamma$-selective substitution $(>99 / 1)$ was observed without any detectable formation of the $\alpha$-substitution product. In contrast, for other allylic electrophiles such behavior in the absence of transition metal catalysts is difficult to control ${ }^{63}$.

Next, to obtain optimal results for this benchmark system, critical reaction parameters were studied in detail (see Supplementary Tables 1-3). The following observations are important to note: (a) It is possible to run the nucleophilic substitution efficiently under very mild conditions (RT to $50{ }^{\circ} \mathrm{C}$ ) in the presence of sub-stoichiometric amounts of base without any metal catalyst (Fig. 2b, entries 3-10); (b) this transformation works well in aqueous solutions as well as pure water and high yields of 3 (up to 94\%) can be obtained, which is interesting for biologically relevant substrates and considering the importance of green solvents (Fig. 2b, entries 6-11)64; (c) using stronger base (sodium hydride), the reaction proceeded smoothly within minutes (typically $<10 \mathrm{~min}$ ) at ambient temperature affording the desired ether product 3 in quantitative yield (Fig. 2b, entry 12). Interestingly, depending on the physical properties of specific substrates, the most suited protocol might be selected from these orthogonal approaches. Similar results were obtained using other 


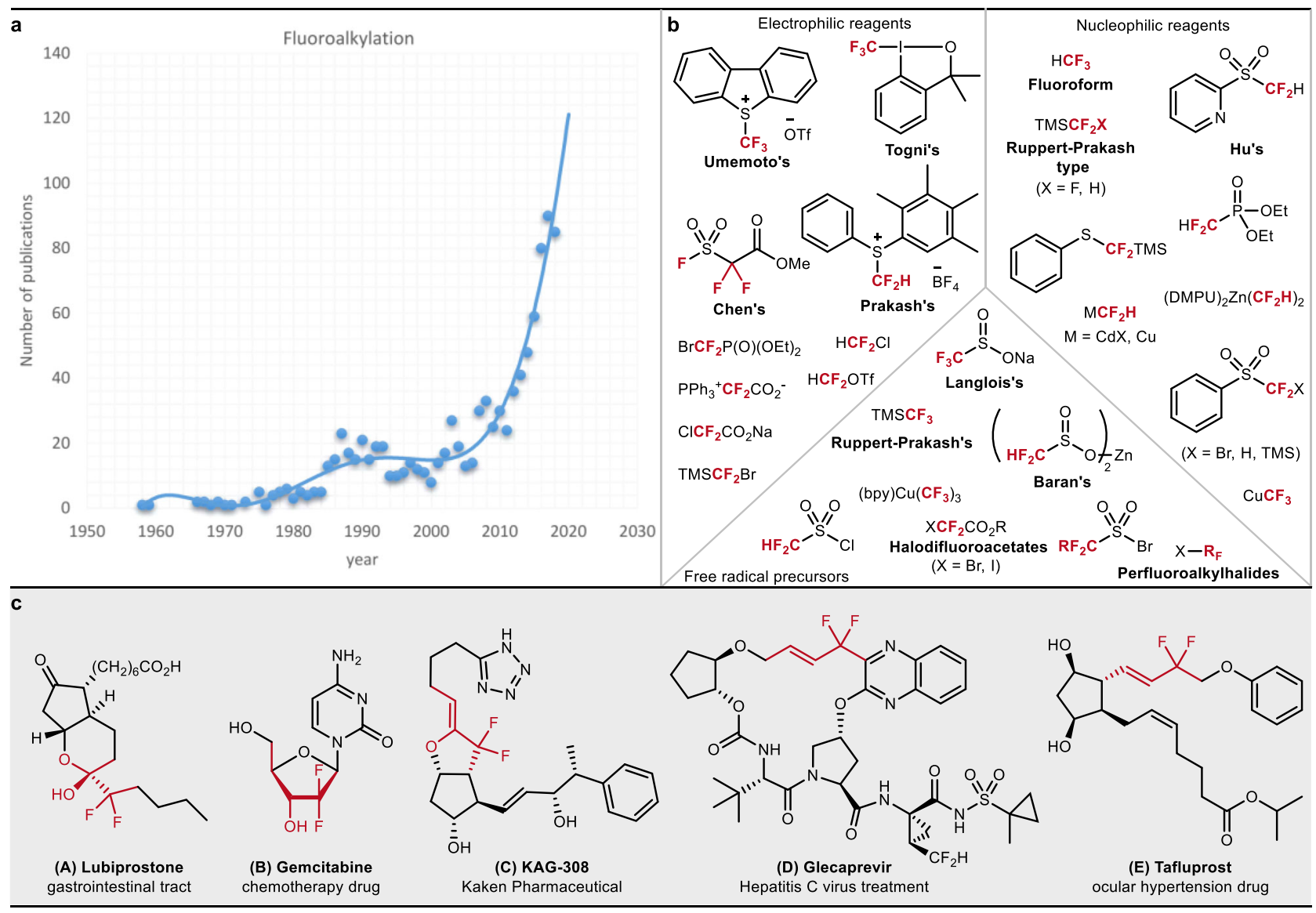

d Previous work
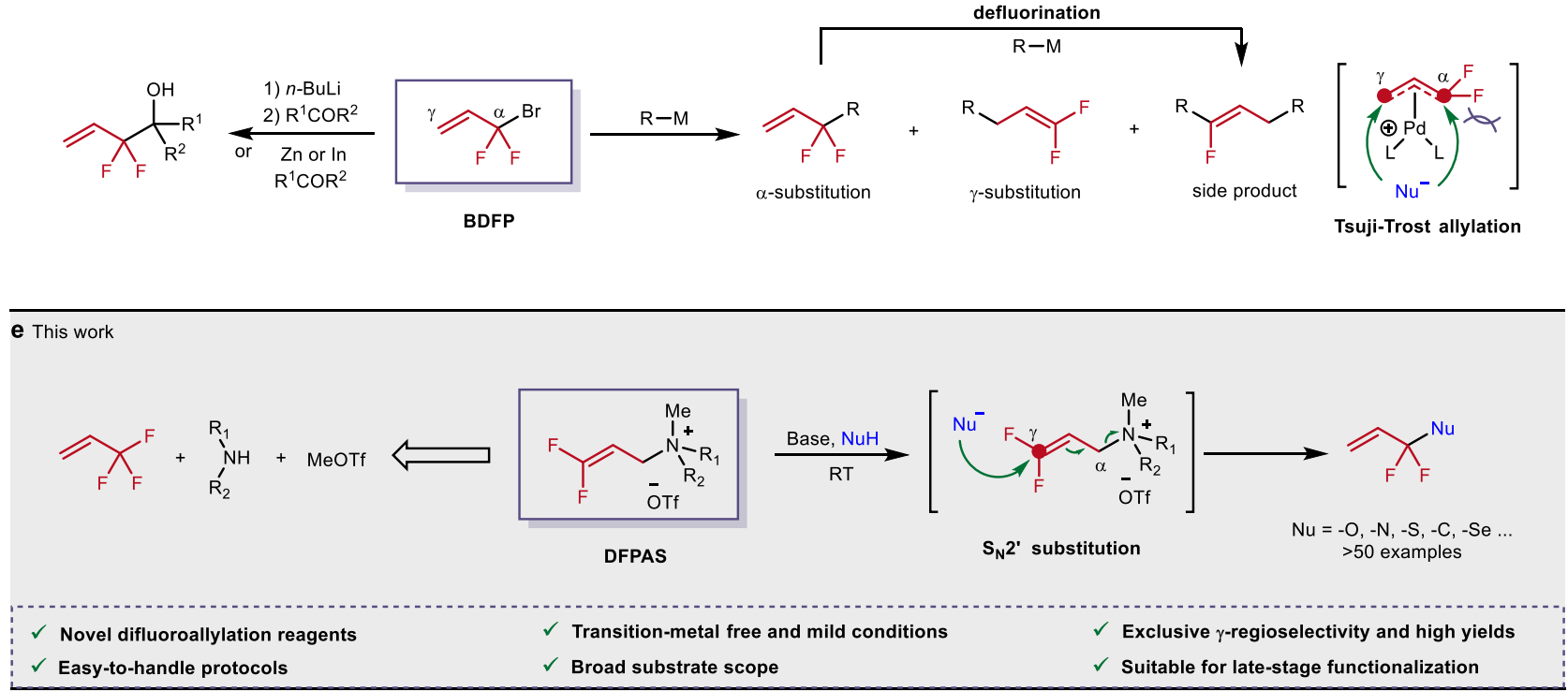

Fig. 1 The allure of fluoroalkylations. a The dynamic development of fluoroalkylations in the past years. $\mathbf{b}$ Commonly used fluoroalkyl-containing reagents for direct preparation of fluoroalkyl compounds. $\mathbf{c}$ The importance of compounds containing difluoromethylene unit. $\mathbf{d}$ The challenge of the direct preparation of gem-difluoroallyl compounds using BDFP. e The presented strategy for the selective construction of gem-difluoroallyl compounds.

related ammonium salts $\mathbf{1 b}-\mathbf{1 e}$ as difluoroallylating reagents (Fig. 2b, entries 13-16).

After having demonstrated the efficiency of the model system at different conditions, we were interested in the general reaction scope. At first, other oxygen nucleophiles were studied. Using $\mathrm{NaH}$ as base, the gem-difluoroallylation of allylic ammonium salt 1a with various phenols provided allylic aryl ethers 3-18 in good to excellent yields. The reaction displayed remarkable compatibility with functional groups including ketones, aldehydes, esters, halides, amines, boronic acidic esters, heterocycles, and alkenes. As shown in the case of product 19, the reaction can be easily run on gram-scale. Apart from phenols, a variety of aliphatic alcohols were successfully examined as well, affording the allylic alkyl ethers 23-27 in 63-99\% yields. From a synthetic point of view, it 
a

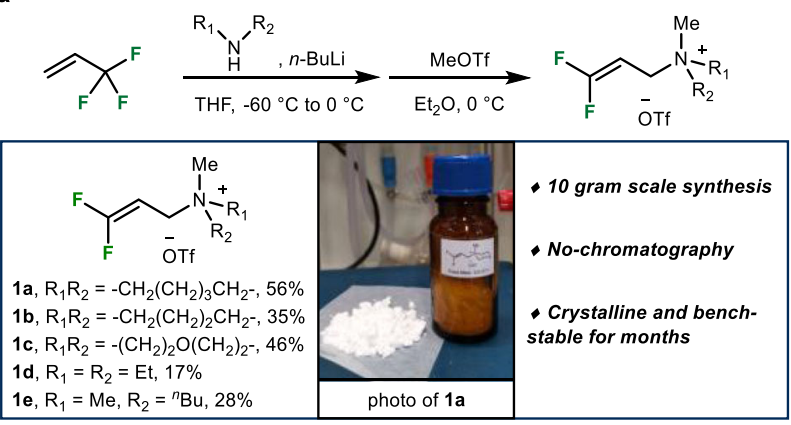

b

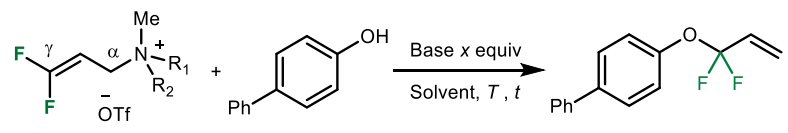

1

2a

\begin{tabular}{|c|c|c|c|c|c|c|}
\hline Entry & 1 & Base ( $x$ equiv) & Solv. (con.) & $\mathrm{T}\left({ }^{\circ} \mathrm{C}\right)$ & $t(\mathrm{~h})$ & yield $(\%)$ \\
\hline $1^{\dagger}$ & 1a & $\mathrm{Cs}_{2} \mathrm{CO}_{3}(1.0)$ & Toluene ( $0.1 \mathrm{M})$ & 80 & 18 & 92 \\
\hline 2 & 1a & $\mathrm{Cs}_{2} \mathrm{CO}_{3}(1.0)$ & Toluene $(0.1 \mathrm{M})$ & 80 & 18 & 87 \\
\hline 3 & $1 \mathrm{a}$ & $\mathrm{Cs}_{2} \mathrm{CO}_{3}(0.5)$ & Toluene $(0.1 \mathrm{M})$ & 80 & 18 & 96 \\
\hline 4 & 1a & $\mathrm{Cs}_{2} \mathrm{CO}_{3}(0.5)$ & Toluene $(0.1 \mathrm{M})$ & 50 & 18 & $>99$ \\
\hline 5 & 1a & $\mathrm{Cs}_{2} \mathrm{CO}_{3}(0.2)$ & Toluene $(0.1 \mathrm{M})$ & 80 & 18 & 59 \\
\hline 6 & $1 \mathrm{a}$ & $\mathrm{K}_{2} \mathrm{CO}_{3}(1.0)$ & $\mathrm{H}_{2} \mathrm{O} / \mathrm{THF}(9: 1,0.1 \mathrm{M})$ & RT & 18 & 49 \\
\hline 7 & 1a & $\mathrm{KOH}(1.0)$ & $\mathrm{H}_{2} \mathrm{O} / \mathrm{THF}(9: 1,0.1 \mathrm{M})$ & RT & 18 & 72 \\
\hline 8 & 1a & $\mathrm{NaOH}(1.0)$ & $\mathrm{H}_{2} \mathrm{O} / \mathrm{THF}(9: 1,0.1 \mathrm{M})$ & RT & 18 & 64 \\
\hline 9 & $1 \mathrm{a}$ & $\mathrm{Cs}_{2} \mathrm{CO}_{3}(1.0)$ & $\mathrm{H}_{2} \mathrm{O} / \mathrm{THF}(9: 1,0.1 \mathrm{M})$ & RT & 18 & 63 \\
\hline 10 & 1a & $\mathrm{Cs}_{2} \mathrm{CO}_{3}(0.5)$ & $\mathrm{H}_{2} \mathrm{O} / \mathrm{THF}(9: 1,0.1 \mathrm{M})$ & 80 & 18 & 94 \\
\hline 11 & $1 \mathrm{a}$ & $\mathrm{Cs}_{2} \mathrm{CO}_{3}(0.5)$ & $\mathrm{H}_{2} \mathrm{O}(0.1 \mathrm{M})$ & 80 & 18 & 90 \\
\hline $12^{\ddagger}$ & 1a & $\mathrm{NaH}(1.5)$ & $\operatorname{DMF}(0.2 \mathrm{M})$ & RT & 0.5 & $>99$ \\
\hline $13^{\ddagger}$ & 1b & $\mathrm{NaH}(1.5)$ & $\operatorname{DMF}(0.2 \mathrm{M})$ & RT & 0.5 & 97 \\
\hline $14^{\ddagger}$ & $1 \mathrm{c}$ & $\mathrm{NaH}(1.5)$ & $\operatorname{DMF}(0.2 \mathrm{M})$ & RT & 0.5 & 97 \\
\hline $15^{\ddagger}$ & 1d & $\mathrm{NaH}(1.5)$ & $\operatorname{DMF}(0.2 \mathrm{M})$ & RT & 0.5 & 98 \\
\hline $16^{\ddagger}$ & $1 e$ & $\mathrm{NaH}(1.5)$ & $\operatorname{DMF}(0.2 \mathrm{M})$ & RT & 0.5 & 90 \\
\hline
\end{tabular}

Fig. 2 Reagent synthesis and model reaction. a Two-step synthesis procedure for the preparation of difluorinated allyl ammonium salts 1a-1e. b Optimization studies for the $\mathrm{S}_{\mathrm{N}} 2^{\prime}$ substitution reaction of difluoroallyl ammonium salt $\mathbf{1 a}$ with 4-phenyl phenol $\mathbf{2}$ in the presence of different basic conditions. ${ }^{\dagger} \mathrm{PdBr}_{2}(0.015 \mathrm{mmol})$ and ${ }^{n} \mathrm{BuPAd}_{2}(0.03 \mathrm{mmol})$ were used.

the reaction was performed under an argon atmosphere.

is also interesting that gem-difluoroallylation of functionalized propargylic alcohols generated versatile diene-ynes (25 and 26) and 1,6-enyne (27). Notably, less common oxygen nucleophiles such as oximes and hydroxylamines also worked well and provided the respective products $\mathbf{2 0 - 2 2}$ in very good yields. Recently, these latter products attracted attention because of their potential application for fluoroalkoxylation of alkyl halides ${ }^{65}$.

In addition to phenols, aliphatic and propargylic alcohols, also diverse sulfur-, selenium-, nitrogen-, as well as activated carbonnucleophiles can be used according to our general protocol as depicted in Fig. 3. More specifically, aryl thiols bearing electrondonating or electron-withdrawing groups and alkyl thiols as well as benzeneselenol underwent the desired the $S$ - or Se-gemdifluoroallylation leading to the corresponding products 28-32. Gratifyingly, these reaction conditions can be used for a broad range of heterocyclic amines and tosyl-protected secondary amines, too. In all cases, the reaction proceeded smoothly to give 33-38 bearing allylic $N$-difluoromethylene unit in high yields.

Next, we turned our attention to the reaction of activated carbon nucleophiles. Interestingly, using ketones with $\beta-\mathrm{H}$ resulted selectively in $\mathrm{O}$-gem-difluoroallylation and provided the corresponding allyl vinyl ethers $\mathbf{3 9 - 4 2}$ as single products in $73-99 \%$ yields. The high carbon/oxygen $(\mathrm{C} / \mathrm{O})$ regioselectivity could be explained by the Pearson acid-base concept ${ }^{66,67}$. On the other hand, using diphenylacetonitrile led to the construction of $\mathrm{C}_{\mathrm{sp} 3}-\mathrm{CF}_{2} \mathrm{R}$ bond (43) and thus to access $\alpha$-difluoroalkylated carboxylic acid derivatives. It is important mentioning that in all cases, the $\alpha / \gamma$-regioselective gem-difluoroallylation undoubtedly generated exclusively the $\gamma$-substitution product. At this point it should be also noted that many difluoroallyl ammonium salts can be used for the preparation of more substituted derivatives following a similar methodology (see Supplementary Fig. 3).

To showcase the value of this synthetic approach, late-stage functionalization of a variety of pharmaceuticals, bioactive molecules, and natural products are depicted in Fig. 4. More specifically, estrone, one of the three major endogenous estrogens, with a phenolic group delivered to the difluoroallylic derivative $\mathbf{4 4}$ in excellent yield (97\%). The molecular structure of 44 was confirmed by X-ray crystallography. Similar transformations performed with the $(+)$ - $\alpha$-tocopherol, acetate-protected $\beta$-estradiol, and diethylstilbestrol afforded the desired products 45-47 with high efficiency (99\%, 97\%, and 92\%, respectively). Furthermore, monoterpene $(Z)$-nerol-known as sweet rose-like aroma -bearing an allylic hydroxyl group, gave the corresponding 1,6,10-triene 48 in 97\% yield. Additionally, several functionalized biologically relevant primary and secondary alcohols and various pharmaceutically important molecules, such as mestranol, lynestrenol, quinine, and testosterone, containing sterically congested tertiary or secondary hydroxyl groups, underwent this reaction smoothly, giving 49-55 in good to excellent yields. Notably, a derivative of the sulfonamide Celecoxib (analgesic) also could be coupled to give the $N$-difluoroallylated product 56 in high yields.

Difluoroallylic $\mathrm{S}_{\mathrm{N}} 2^{\prime}$ substitution of different substrates containing more than one activated proton further highlights the importance of this method, especially in the late-stage functionalization of bioactive molecules. To ensure chemoselectivity, the milder base $\mathrm{Cs}_{2} \mathrm{CO}_{3}$ was applied in these examples. For example, ezetimibe, an FDA-approved drug for the treatment of high blood cholesterol and certain other lipid abnormalities, underwent selective gem-difluoroallylation to give $\mathbf{6 0}$ in $84 \%$ yield. This demonstrates the compatibility of the reaction conditions with aliphatic hydroxyl groups and an amide-activated $\beta$-protons. In addition, transformations of $N$-Boc-protected $L$-tyrosine derivative, ethynylestradiol, and $\beta$-estradiol afforded the desired products 57-59 in high yields.

After validating the generality of our protocol and having a selection of allylic gem-difluoride building blocks in hand, we wanted to demonstrate their value by further valorizations (Fig. 5). Exemplarily, we first carried out the Pd-catalyzed alkoxycarbonylation of gem-difluoroallylic aryl ether $\mathbf{3}$ without further optimizations. Taking advantage of the specific phosphine ligand L1 with built-in-base functions ${ }^{68,69}$, the corresponding product $\mathbf{6 1}$ was obtained in $73 \%$ yield with high regioselectivity for the linear product. Furthermore, under-reported reaction conditions $^{70}, 3$ underwent highly regioselective hydroformylation using simple $\mathrm{Co}_{2}(\mathrm{CO})_{8}$ as the pre-catalyst ( $87 \%$ yield, $l / b>20 / 1$ ).

Apart from aldehydes and carboxylic acids, the difluorinated products constitute virtuous precursors for the synthesis of other multifunctional compounds. For example, dihydroxylation of $\mathbf{1 6}$ and 23 provided the corresponding difluoromethylated glycerol derivatives 63 and 64 in quantitative yields (Fig. 5b). These 

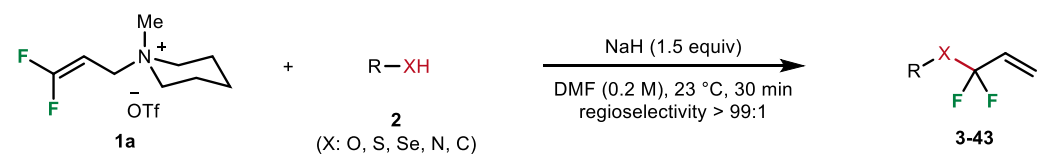

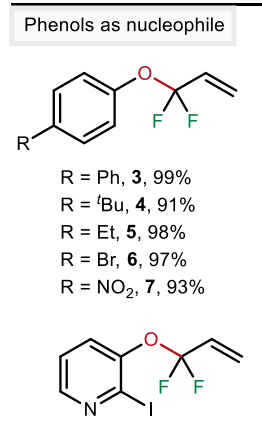

$13,88 \%$<smiles>C=CC(F)(F)Oc1ccc(C(C)=O)cc1</smiles>

$8,85 \%$<smiles>C=CC(F)(F)Oc1ccc(C(=O)c2ccccc2)cc1</smiles>

$9,98 \%$<smiles>C=CC(F)(F)Oc1ccccc1CO</smiles>

$10,76 \%$<smiles>C=CC(F)(F)Oc1ccc(C(C)=O)cc1I</smiles>

$11,86 \%$<smiles>C=CC(F)(F)Oc1c(F)cccc1F</smiles>

$12,92 \%$<smiles>C=CC(F)(F)Oc1ccc(OCCCC)cc1</smiles>

$14,99 \%$<smiles>C=CC(F)(F)Oc1ccc(B2OC(C)(C)C(C)(C)O2)cc1</smiles>

$15,68 \%(95 \%)$ $\mathrm{N}$-hydroxy as nucleophlie<smiles>C=CC(F)(F)Oc1cccc2ccccc12</smiles>

$16,99 \%$<smiles>C=CC(F)(F)Oc1ccc(-n2ccnc2)cc1</smiles>

$17,99 \%$<smiles>C=CC(F)(F)Oc1ccc(-c2nc(C)c(C(C)=O)s2)cc1CO</smiles>

$18,78 \%$<smiles>C=CC(F)(F)Oc1ccc2c(c1)NC(=O)CC2</smiles>

$19,90 \%{ }^{\dagger}(1 \mathrm{~g}$ scale $)$<smiles>C=CC(F)(F)ON1C(=O)c2ccccc2C1=O</smiles>

$20,50 \%(95 \%)$<smiles>C=CC(F)(F)ON=Cc1ccccc1</smiles>

21, $99 \%$<smiles>C=CC(F)(F)ON1C2CC3CC(C3)CC21</smiles>

22, $96 \%$

Alkyl alcohols as nucleophlie<smiles>C=CC(F)(F)OCCc1cccc2ccccc12</smiles>

23, $95 \%$

Thiols as nucleophile<smiles>C=CC(F)(F)OCc1ccc(C=O)o1</smiles>

$24,63 \%$<smiles>C=CC(F)(F)OCC#CCOC(F)(F)C=C</smiles>

25, $90 \%$<smiles>C=CCNCC#CCOC(F)(F)C=C</smiles>

26, $81 \%$<smiles>C=CC(F)(F)OCC#Cc1ccccc1</smiles>

$27,99 \%$ Selenol as nucleophile<smiles>C=CC(F)(F)Sc1ccc(-c2ccc(SC(F)(F)C=C)cc2)cc1</smiles>

$28,88 \%$<smiles>FC(F)(F)Sc1ccc(Cl)cc1</smiles>

29, $91 \%$<smiles>C=CC(F)(F)Sc1cccc2ccccc12</smiles>

$30,95 \%$<smiles>C=CC(F)(F)SCc1ccccc1</smiles>

$31,95 \%$<smiles>C=CC(F)(F)[Se]c1ccccc1</smiles>

32, $97 \%$

Amines as nucleophile

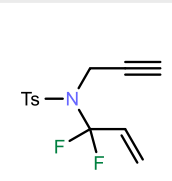

33, $94 \%$<smiles>C=CC(F)(F)n1cc(C(=O)OC(C)(F)F)cn1</smiles>

34, $99 \%$<smiles>C=CC(F)(F)n1nc(Cl)c2ccccc21</smiles>

$35,92 \%$<smiles>C=CC(F)(F)n1cnc2ccccc21</smiles>

36, $95 \%$<smiles>C=CC(F)(F)n1nnc2ccccc21</smiles>

$37,96 \%$<smiles>C=CC(F)(F)n1cnc(-c2ccccc2)c1-c1ccccc1</smiles>

$38,96 \%$<smiles>C=CC(F)(F)OC(=Cc1ccc(OC)cc1)c1ccc(OC)cc1</smiles>

39, $77 \%$<smiles>C=CC(F)(F)OC(=C)c1ccc2ccccc2c1</smiles>

40, $73 \%$<smiles>C=CC(F)(F)OC(=C)c1cccc(C(F)(F)F)c1</smiles>

$41,81 \%$<smiles>C=CC(F)(F)OC(=C)c1cccc(Br)c1</smiles>

42, $99 \%$

Carbon nucleophile

Fig. 3 Regioselective substitution of $\mathbf{1 a}$ by different $\mathbf{0}-, \mathbf{N}-$, S-, Se- and C-nucleophiles: Substrate scope. Standard reaction conditions: 1 (1.2 equiv), 2 (1 equiv), $\mathrm{NaH}$ (1.5 equiv) in DMF $(0.2 \mathrm{M})$, the reaction mixture was performed at $23^{\circ} \mathrm{C}$ under argon atmosphere for $30 \mathrm{~min}$, isolated yield, the $\alpha / \gamma$ regioselectivity was determined by crude ${ }^{19} \mathrm{~F}$ NMR analyses. ${ }^{\dagger} \mathrm{Cs}_{2} \mathrm{CO}_{3}(0.5$ equiv) and toluene $(0.1 \mathrm{M})$ were used as base and solvent, the reaction was performed at $50^{\circ} \mathrm{C}$ under air atmosphere for $18 \mathrm{~h}$. 
<smiles>[R]N[N+]([O-])(CC=C(F)F)CCCBr</smiles>

1a

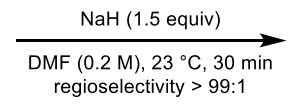

regioselectivity $>99: 1$<smiles>[R][X]C(F)(F)C=C</smiles>

$44-60$<smiles>C#CCC1CCC2C1(C)CCC1c3ccc(OC(F)(F)C=C)cc3CC[C@]12C</smiles>

44, 97\%, from Estrone<smiles>C=CC(F)(F)Oc1ccc2c(c1)CC[C@@H]1[C@@H]2CC[C@@]2(C)[C@H]1CC[C@H]2OC(C)=O</smiles>

46, $97 \%$, from $\beta$-Estradiol

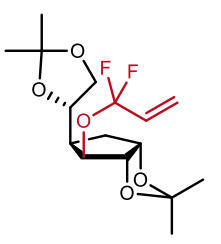

50, $92 \%$, from 1,2:5,6-Di-O-isopropylidene$\alpha$-D-glucofuranose

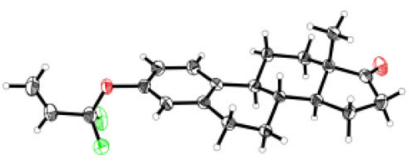

Displacement ellipsoid plot ( $50 \%$ probability level) of 44<smiles>C=CC(F)(F)Oc1ccc(/C(CC)=C(\CC)c2ccc(OC(F)(F)C=C)cc2)cc1</smiles>

47, $92 \%$, from Diethylstilbestrol

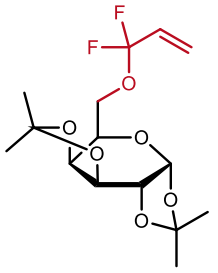

51, 99\%, from 1,2:3,4-Di-O-isopropylidene$\alpha$-D-galactopyranose

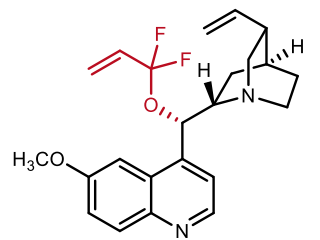

54, $98 \%$, from Quinine

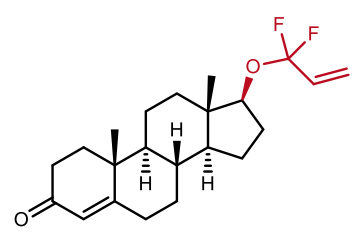

$\mathbf{5 5}, 67 \%$, from Testosterone<smiles>C=CCN(C(F)(F)C=C)S(=O)(=O)c1ccc(-n2nc(C(F)(F)F)cc2-c2ccc(C)cc2)cc1</smiles>

56, $96 \%$, from Celecoxib<smiles>C=CC(F)(F)OCC=C(C)CCC=C(C)C</smiles>

48, $97 \%$, from (Z)-Nerol<smiles>C=CC(F)(F)O[C@H]1CO[C@@H]2[C@@H](OC(F)(F)C=C)CO[C@@H]12</smiles>

49, $98 \%$, from Isosorbide<smiles>C#C[C@]12CC[C@H]3c4ccc(OC)cc4CC[C@H]3C1CCC2(C=C)OC(F)(F)F</smiles>

52, $98 \%$, from Mestranol

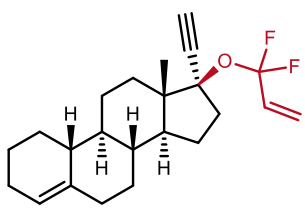

53 99\%, from Lynestrenol<smiles>C=CC(C)(F)Oc1ccc(C[C@H](N)C(=O)OC)cc1I</smiles>

$\mathbf{5 7}, 94 \%,{ }^{\dagger}$ from iodinated $L$-tyrosine

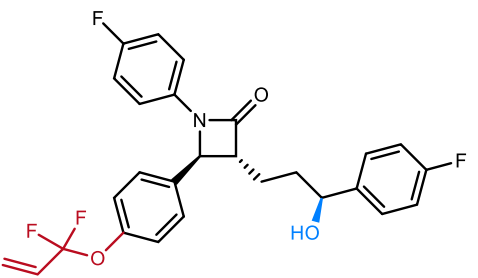

$60,84 \%,{ }^{\dagger}$ from Ezetimibe

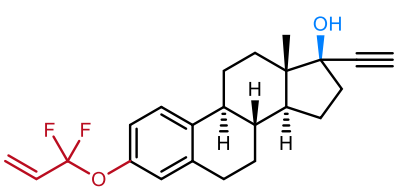

$\mathbf{5 8}, \mathbf{9 3} \%,{ }^{\dagger}$ from Ethynylestradiol

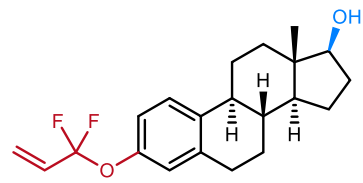

$\mathbf{5 9}, 81 \%,{ }^{\dagger}$ from $\beta$-Estradiol

Fig. 4 Selective 1,1-difluoroallylation of natural products and pharmaceuticals. Standard reaction conditions: 1a (1.2 equiv), 2 (1 equiv), NaH (1.5 equiv) in $\operatorname{DMF}(0.2 \mathrm{M})$, the reaction mixture was performed at $23^{\circ} \mathrm{C}$ under argon atmosphere for $30 \mathrm{~min}$, isolated yield, the $\alpha / \gamma$ regioselectivity was determined by crude ${ }^{19} \mathrm{~F}$ NMR analyses. ${ }^{\dagger} \mathrm{Cs}_{2} \mathrm{CO}_{3}\left(0.5\right.$ equiv) and toluene $(0.1 \mathrm{M})$ were used as base and solvent, the reaction was performed at $50{ }^{\circ} \mathrm{C}$ under air atmosphere for $18 \mathrm{~h}$.

compounds are of interest as potential precursors for the preparation of difluorinated propranolol and many other analogs of beta blocker pharmaceuticals ${ }^{71}$.

Considering transition-metal-catalyzed carbocycloaddition reactions as powerful methods for the construction of polyheterocycles ${ }^{72}$, products 26 and 27 were examined following previously reported protocols. Indeed, starting from diene-yne $\mathbf{2 6}$, an intramolecular ruthenium-catalyzed $[2+2+2]$ co-cyclization took place to yield the N,O-fused tricyclic heterocycle $\mathbf{6 5}$ in $69 \%$ yield, albeit with moderate diastereoselectivity. The asymmetric version of rhodium-catalyzed reductive cyclization of 1,6-enyne 27 successfully proceeded at ambient temperature and hydrogen pressure, affording the gem-difluorinated alkylidene-substituted furan 66 in excellent yield and high enantioselectivity ( $97 \%$ yield, $92 \% e e)$.

Finally, two gem-difluoromethylene-containing analogs of actual drug compounds were prepared using the here presented methodology. Aripiprazole is an antipsychotic drug, ranking 128th among the top 200 retail drugs in 2019 with annual sales $>1.2$ billion dollars ${ }^{73}$. In a straightforward manner the $\mathrm{O}_{-} \mathrm{CF}_{2^{-}}$ derivative of aripirazole was successfully synthesized from commercially available materials, as illustrated in Fig. 5e. After highly regioselective hydroformylation of difluoroallylic aryl ether 19, followed by subsequent reduction, mesylation, and final $\mathrm{S}_{\mathrm{N}} 2$ substitution, the desired difluorinated aripiprazole $\mathbf{7 0}$ was obtained in $68 \%$ overall yield. As the second example, the 


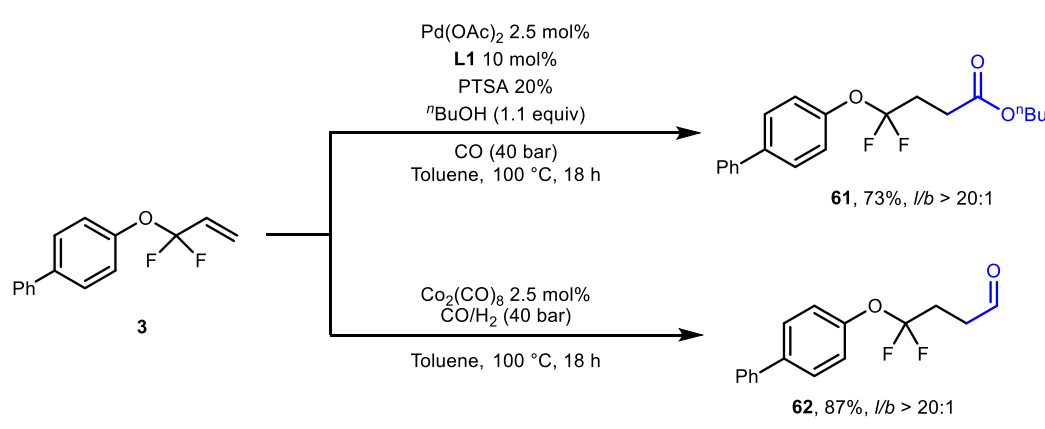

b
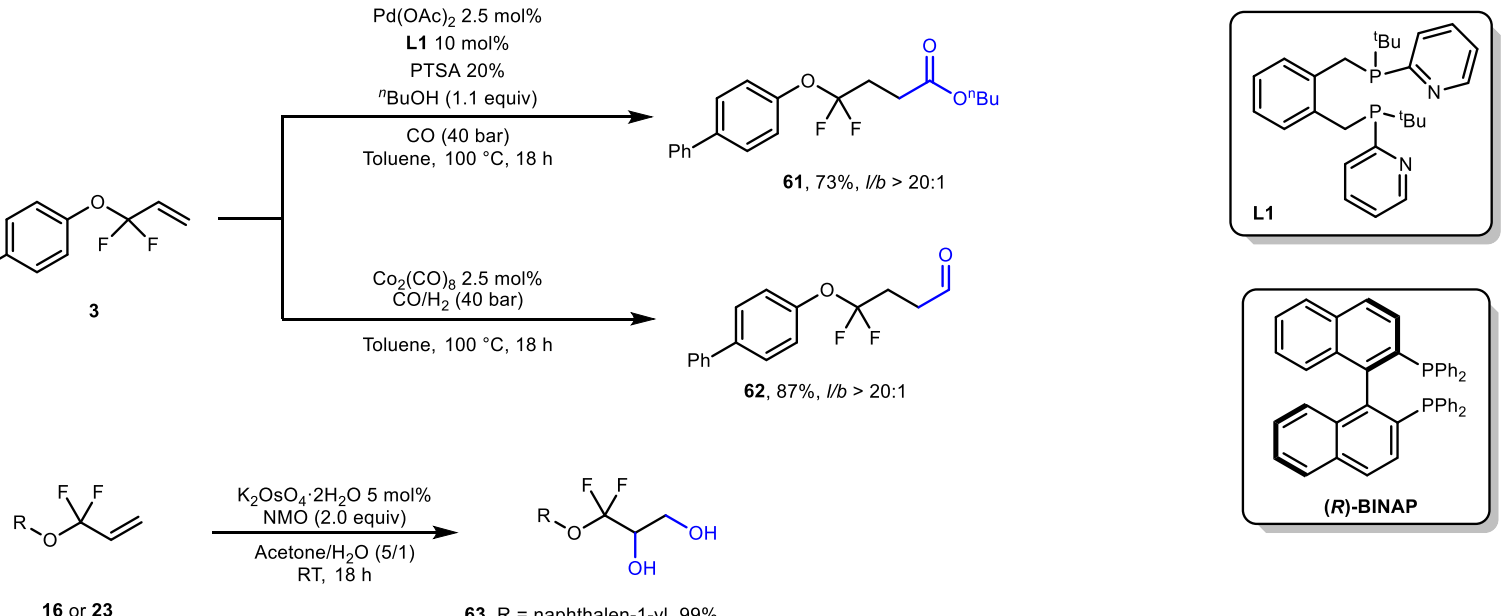

63, $R=$ naphthalen-1-yl, 99\%

64, $R=2$-(naphthalen-1-yl)ethyl, $99 \%$<smiles>C=CC[N]CC#CCOC(F)(F)C=C</smiles>

26

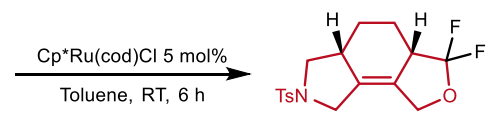

$\mathbf{6 5}, 69 \%(\mathrm{dr}=4.5: 1, \mathrm{NMR})$

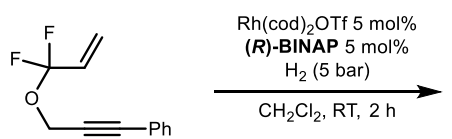

27

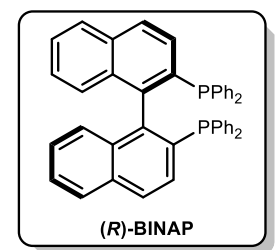

e

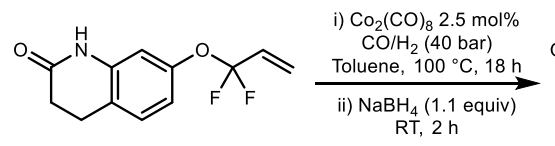

19

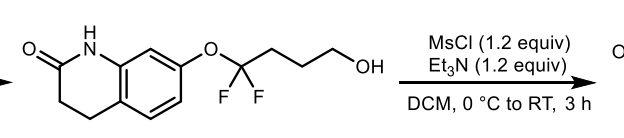

67, 95\% (two step)<smiles>CS(=O)(=O)OCCCC(F)(F)Oc1ccc2c(c1)NC(=O)CC2</smiles>

$68,96 \%$

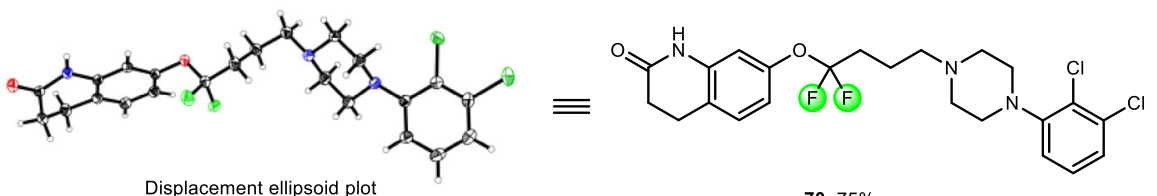
Displacement ellipsoid plot
(50\% probability level) of 70 $70,75 \%$<smiles>O=C1CCc2ccc(OCCCCN3CCN(c4cccc(Cl)c4Cl)CC3)cc2N1</smiles>

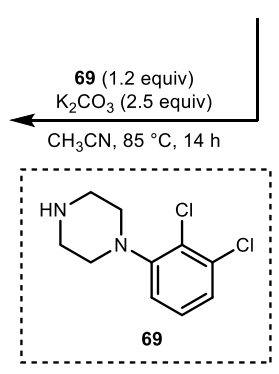

f

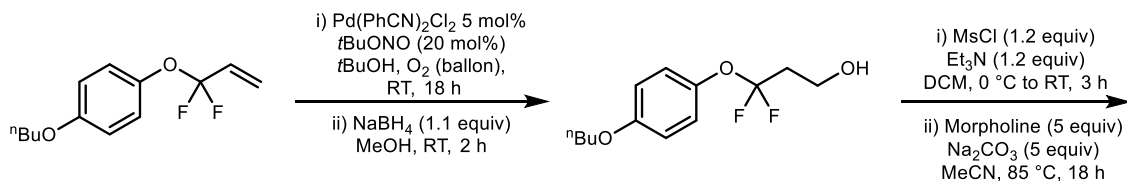

14

$\mathbf{7 1}, 62 \%$ (two step)<smiles>CCCCOc1ccc(OCCCN2CCOCC2)cc1</smiles>

Fig. 5 Synthesis of $\mathbf{g e m}$-difluorinated analogs of drugs and further valorization of $\boldsymbol{g e m}$-difluorinated allyl ethers. a Transition-metal catalyzed carbonylation of difluorinated alkene $\mathbf{3}$. b Dihydroxylation of $\mathbf{1 6}$ and $\mathbf{2 3}$ to give difluorinated 1-aryl-glycerols. c Ruthenium-catalyzed [2 $+2+2$ ] co-

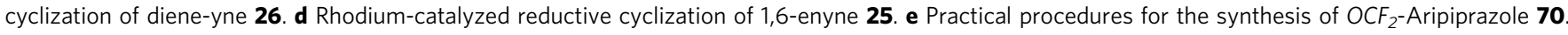
f Four-step protocol for the synthesis of $\mathrm{OCF}_{2}$-Pramocaine $\mathbf{7 3 .}$ 
$\mathrm{CF}_{2}$-analog of Pramocaine (a topical anesthetic) was prepared easily in four steps in 53\% overall yield (Fig. 5f).

In summary, we present the parent examples of DFPAs, which can be easily prepared by base-mediated amination of the industrial feedstock 3,3,3-trifluoropropene. The resulting compounds are air-stable and water-stable and can be conveniently applied as highly efficient difluoromethylene reagents. Following an operationally simple and scalable protocol various nucleophiles including phenols, alcohols, thiols, selenols, amines, ketones, and alkanes with activated $\mathrm{C}_{\mathrm{sp} 3}-\mathrm{H}$ undergo exclusively $\gamma$-regioselectivity gem-difluoroallylation without the need of transition-metals under mild conditions. So far, the resulting allylic gem-difluoromethylated products were difficult to access by using conventional approaches. The successful incorporation of the allylic difluoromethylene unit into a wide variety of bioactive pharmaceuticals and natural products provides chemists a new route to explore fluorinecontaining molecular scaffolds.

\section{Methods}

General procedure A for the preparation of allylic gem-difluoromethylated compounds. To a $25 \mathrm{~mL}$ oven-dried pressure tube equipped with a magnetic stir bar were added difluoroallyl ammonium salt $\mathbf{1}(0.36 \mathrm{mmol}), \mathrm{NaH}(0.45 \mathrm{mmol})$, DMF $(1.5 \mathrm{~mL})$, and then nucleophiles $2(0.3 \mathrm{mmol})$ was introduced under argon atmosphere. The sealed pressure tube was vigorously stirred at $23^{\circ} \mathrm{C}$ for $30 \mathrm{~min}$ The reaction mixture was quenched with few drops of water and extracted with ethyl acetate $(3 \times 20 \mathrm{~mL})$. The combined organic layer was dried over anhydrous $\mathrm{Na}_{2} \mathrm{SO}_{4}$, filtered and concentrated. The residue was purified by chromatography on silica gel (It is worthy to note that some of the fluorinated product can only be separated without decomposition with $2 \%$ triethylamine in the eluent) to afford the desired product.

\section{General procedure B for the preparation of allylic gem-difluoromethylated} compounds. To a pressure tube $(25 \mathrm{~mL})$ equipped with a magnetic stir bar difluoroallyl ammonium salt $1(0.36 \mathrm{mmol}), \mathrm{Cs}_{2} \mathrm{CO}_{3}(0.15 \mathrm{mmol})$, toluene $(2.5 \mathrm{~mL})$, and then nucleophiles $2(0.3 \mathrm{mmol})$ were added. The sealed pressure tube was vigorously stirred for $18 \mathrm{~h}$ at $50^{\circ} \mathrm{C}$ under air atmosphere. After cooling to r.t., the reaction mixture was diluted with ethyl acetate $(10 \mathrm{~mL})$ and filtered through a short pad of celite eluting with ethyl acetate $(3 \times 10 \mathrm{~mL})$. After evaporation, the residue was purified by chromatography on silica gel to afford the desired product. Notably, some of the fluorinated products can only be separated without decomposition with $2 \%$ triethylamine in the eluent.

\section{Data availability}

The authors declare that all the data supporting this study, including the experimental details, data analysis, and spectra for all unknown compounds, see Supplementary Files. All data underlying the findings of this work are available from the corresponding author upon reasonable request. The X-ray crystallographic coordinates for structures reported in this study have been deposited at the Cambridge Crystallographic Data Centre (CCDC), under deposition numbers 2035829 (44) and 2035828 (70). These data are provided free of charge by the joint Cambridge Crystallographic Data Centre and Fachinformationszentrum Karlsruhe Access Structures service www.ccdc.cam.ac.uk/ structures.

Received: 2 March 2021; Accepted: 30 April 2021;

Published online: 31 May 2021

\section{References}

1. Hird, M. Fluorinated liquid crystals-properties and applications. Chem. Soc. Rev. 36, 2070-2095 (2007).

2. Müller, K., Faeh, C. \& Diederich, F. Fluorine in pharmaceuticals: looking beyond intuition. Science 317, 1881-1886 (2007).

3. Purser, S., Moore, P. R., Swallow, S. \& Gouverneur, V. Fluorine in medicinal chemistry. Chem. Soc. Rev. 37, 320-330 (2008).

4. Smits, R., Cadicamo, C. D., Burger, K. \& Koksch, B. Synthetic strategies to atrifluoromethyl and $\alpha$-difluoromethyl substituted $\alpha$-amino acids. Chem. Soc. Rev. 37, 1727-1739 (2008).

5. Siegemund, G. et al. Ullmann's Encyclopedia of Industrial Chemistry: Fluorine Compounds, Organic (Wiley-VCH Verlag GmbH \& Co. KGaA, Weinheim, 2012).
6. Groult, H., Leroux, F. \& Tressaud, A. Modern Synthesis Processes and Reactivity of Fluorinated Compounds (Elsevier, 2016).

7. Sedelmeier, G. \& Sedelmeier, J. Top 200 drugs by worldwide sales 2016. CHIMIA 71, 730-730 (2017).

8. Jarvis, L. M. The new drugs of 2018. Chem. Eng. News. https://cen.acs.org/ pharmaceuticals/drug-development/new-drugs-2018/97/i3 (2018).

9. Jarvis, L. M. The new drugs of 2019. Chem. Eng. News. https://cen.acs.org/ pharmaceuticals/drug-development/new-drugs-2019/98/i3 (2019).

10. Data Obtained by Searching Keywords on the Website of Science Finder. https://scifinder.cas.org/ (2020).

11. Charpentier, J., Früh, N. \& Togni, A. Electrophilic trifluoromethylation by use of hypervalent iodine reagents. Chem. Rev. 115, 650-682 (2015).

12. Ni, C. F., Hu, M. \& Hu, J. Good partnership between sulfur and fluorine: sulfur-based fluorination and fluoroalkylation reagents for organic synthesis. Chem. Rev. 115, 765-825 (2015).

13. Liang, T., Neumann, C. N. \& Ritter, T. Introduction of fluorine and fluorinecontaining functional groups. Angew. Chem. Int. Ed. 52, 8214-8264 (2013).

14. Prakash, G. K. S. \& Yudin, A. K. Perfluoroalkylation with organosilicon reagents. Chem. Rev. 97, 757-786 (1997).

15. Xu, L. \& Vicic, D. A. Direct difluoromethylation of aryl halides via base meta catalysis at room temperature. J. Am. Chem. Soc. 138, 2536-2539 (2016).

16. Hill, D. R. et al. Development of a large-scale route to glecaprevir: synthesis of the side chain and final assembly. Org. Process Res. Dev. 24, 1393-1404 (2020).

17. Cink, R. D. et al. Development of the enabling route for glecaprevir via ringclosing metathesis. Org. Process Res. Dev. 24, 183-200 (2020).

18. Krupa, M., Chodyński, M., Ostaszewska, A., Cmoch, P. \& Dams, I. A novel convergent synthesis of the potent antiglaucoma agent tafluprost. Molecules 22, 217 (2017).

19. Watanabe, Y. et al. KAG-308, anewly-identified EP4-selective agonist shows efficacy for treating ulcerative colitis and can bring about lower risk of colorectal carcinogenesis by oral administration. Eur. J. Pharmacol. 754, 179-189 (2015).

20. Taylor, J. G. et al. Discovery of the pan-genotypic hepatitis C virus NS3/4A protease inhibitor voxilaprevir (GS-9857): a component of Vosevi ${ }^{\circledR}$. Bioorg. Med. Chem. Lett. 29, 2428-2436 (2019).

21. Alberico, D., Clayton, J., Gorin, B. I. \& Oudenes, J. Prostaglandin synthesis and intermediates for use therein. US20100056808A1 (2010).

22. Kučera, R., Goetzke, F. W. \& Fletcher, S. P. An asymmetric Suzuki-Miyaura approach to prostaglandins: synthesis of tafluprost. Org. Lett. 22, 2991-2994 (2020).

23. Brown, K., Weymouth-Wilson, A. \& Linclau, B. A linear synthesis of gemcitabine. Carbohyd. Res. 406, 71-75 (2015).

24. Tozer, M. J. \& Herpin, T. F. Methods for the synthesis of gemdifluoromethylene compounds. Tetrahedron 52, 8619-8683 (1996).

25. Bunnelle, W. H., McKinnis, B. R. \& Narayanan, B. A. Difluorination of esters Preparation of alpha, alpha-difluoro ethers. J. Org. Chem. 55, 768-770 (1990)

26. Middleton, W. J. New fluorinating reagents. Dialkylaminosulfur fluorides. J. Org. Chem. 40, 574-578 (1975).

27. Zhou, Q. et al. Direct synthesis of fluorinated heteroarylether bioisosteres. Angew. Chem. Int. Ed. 52, 3949-3952 (2013).

28. Xiao, Y.-L., Min, Q.-Q., Xu, C., Wang, R.-W. \& Zhang, X. Nickel-catalyzed difluoroalkylation of (hetero)arylborons with unactivated 1-bromo-1,1difluoroalkanes. Angew. Chem. Int. Ed. 55, 5837-5841 (2016).

29. An, L., Xu, C. \& Zhang, X. Highly selective nickel-catalyzed gemdifluoropropargylation of unactivated alkylzinc reagents. Nat. Commun. 8, 1460 (2017).

30. Yu, Y.-B., He, G.-Z. \& Zhang, X. Synthesis of a,a-difluoromethylene alkynes by palladium-catalyzed gem-difluoropropargylation of aryl and alkenyl boron reagents. Angew. Chem. Int. Ed. 53, 10457-10461 (2014).

31. Feng, Z., Min, Q.-Q., Fu, X.-P., An, L. \& Zhang, X. Chlorodifluoromethanetriggered formation of difluoromethylated arenes catalysed by palladium. Nat. Chem. 9, 918-923 (2017).

32. Feng, Z., Xiao, Y.-L. \& Zhang, X. Transition-metal (Cu, Pd, Ni)-catalyzed difluoroalkylation via cross-coupling with difluoroalkyl halides. Acc. Chem. Res. 51, 2264-2278 (2018).

33. Fu, X.-P. et al. Controllable catalytic difluorocarbene transfer enables access to diversified fluoroalkylated arenes. Nat. Chem. 11, 948-956 (2019).

34. Min, Q.-Q., Yin, Z., Feng, Z., Guo, W.-H. \& Zhang, X. Highly selective gemdifluoroallylation of organoborons with bromodifluoromethylated alkenes catalyzed by palladium. J. Am. Chem. Soc. 136, 1230-1233 (2014).

35. Fujita, T., Sugiyama, K., Sanada, S., Ichitsuka, T. \& Ichikawa, J. Platform for ring-fluorinated benzoheterole derivatives: palladium-catalyzed regioselective 1,1-difluoroallylation and heck cyclization. Org. Lett. 18, 248-251 (2016).

36. Cogswell, T. J., Dahlen, A. \& Knerr, L. Synthesis of diverse a-fluoroalkoxyaryl derivatives and their use for the generation of fluorinated macrocycles. Chem. Eur. J. 25, 1184-1187 (2019).

37. Zhang, B. \& Zhang, X. Pd-catalyzed gem-difluoroallylation of arylboronic acids with a,a-difluoroallylic acetates. Chem. Commun. 52, 1238-1241 (2016). 
38. Tang, L., Liu, Z.-Y., She, W. \& Feng, C. Selective single C-F bond arylation of trifluoromethylalkene derivatives. Chem. Sci. 10, 8701-8705 (2019).

39. Belhomme, M.-C., Poisson, T. \& Pannecoucke, X. Copper catalyzed a-difluoroacetylation of dihydropyrans and glycals by means of direct $\mathrm{C}-\mathrm{H}$ functionalization. Org. Lett. 15, 3428-3431 (2013).

40. Sato, K., Omote, M., Ando, A. \& Kumadaki, I. Reactions of ethyl bromodifluoroacetate in the presence of copper powder. J. Fluor. Chem. 125, 509-515 (2004).

41. Schwaebe, M. K., McCarthy, J. R. \& Whitten, J. P. Nickel(0)-catalyzed coupling of vinylzirconiums to $\alpha$-bromo- $\alpha \alpha$-difluoro esters. Convenient generation of a functionalized allyldifluoro moiety. Tetrahedron Lett. 41, 791-794 (2000).

42. Li, G. et al. Nickel-catalyzed decarboxylative difluoroalkylation of $a, \alpha-$ unsaturated carboxylic acids. Angew. Chem. Int. Ed. 55, 3491-3495 (2016)

43. Wu, G. \& Wangelin, A. J. Stereoselective cobalt-catalyzed halofluoroalkylation of alkynes. Chem. Sci. 9, 1795-1802 (2018)

44. Feng, Z., Min, Q.-Q., Zhao, H.-Y., Gu, J.-W. \& Zhang, X. A general synthesis of fluoroalkylated alkenes by palladium-catalyzed Heck-type reaction of fluoroalkyl bromides. Angew. Chem. Int. Ed. 54, 1270-1274 (2015).

45. Guo, W.-H., Zhao, H.-Y., Luo, Z.-J., Zhang, S. \& Zhang, X. Fluoroalkylation -borylation of alkynes: an efficient method to obtain (Z)-tri- and tetrasubstituted fluoroalkylated alkenylboronates. ACS Catal. 9, 38-43 (2019).

46. Li, Z., Cui, Z. \& Liu, Z.-Q. Copper- and iron-catalyzed decarboxylative tri- and difluoromethylation of $\alpha, \alpha$-unsaturated carboxylic acids with CF3SO2Na and (CF2HSO2)2Zn via a radical process. Org. Lett. 15, 406-409 (2013).

47. Qing, F.-L. 3-Bromo-3,3-Difluoropropene. e-EROS Encylcopedia of Orgnic Synthesis (John Wiley \& Sons, Ltd., 2005).

48. Tellier, F., Duffault, J.-M., Baudry, M. \& Sauvêtre, R. Reactivity of 1-bromo1,1-difluoro-2-alkenes synthesis of 1,1-difluoroolefins. J. Fluor. Chem. 91, 133-139 (1998).

49. Yue, X., Qiu, X. \& Qing, F. Metal-mediated gem-difluoroallylation of Nacylhydrazones: highly efficient synthesis of $\alpha, \alpha$-difluorohomoallylic amines. Chin. J. Chem. 27, 141-150 (2009).

50. Seyferth, D., Simon, R. M., Sepelak, D. J. \& Klein, H. A. gem-(Difluoroallyl) lithium: preparation by lithium-halogen exchange and utilization in organosilicon and organic synthesis. J. Am. Chem. Soc. 105, 4634-4639 (1983).

51. Menschutkin, N. Beiträge zur Kenntnis der Affinitätskoeffizienten der Alkylhaloide und der organischen Amine. Z. Phys. Chem. 5, 589-600 (1890).

52. Soheili, A. \& Tambar, U. K. Tandem catalytic allylic amination and $[2,3]-$ Stevens rearrangement of tertiary amines. J. Am. Chem. Soc. 133, 12956-12959 (2011).

53. West, T. H., Daniels, D. S., Slawin, A. M. \& Smith, A. D. An isothioureacatalyzed asymmetric [2,3]-rearrangement of allylic ammonium ylides. J. Am. Chem. Soc. 136, 4476-4479 (2014).

54. Arfaoui, A., Saâdi, F., Nefzi, A. \& Amri, H. Easy conversion of dimethyla(bromomethyl)fumarate into functionalized allyl ethers mediated by DABCO. Synth. Commun. 45, 2627-2635 (2015).

55. Baidya, M., Remennikov, G. Y., Mayer, P. \& Mayr, H. SN2' versus SN2 reactivity: control of regioselectivity in conversions of Baylis-Hillman adducts. Chem. Eur. J. 16, 1365-1371 (2010).

56. Ye, F., Ge, Y., Spannenberg, A. H., Neumann \& Beller, M. The role of allyl ammonium salts in palladium-catalyzed cascade reactions towards the synthesis of spiro-fused heterocycles. Nat. Commun. 11, 5383 (2020).

57. He, L. et al. Heterogeneous platinum-catalyzed C-H perfluoroalkylation of arenes and heteroarenes. Angew. Chem. Int. Ed. 54, 4320-4324 (2015).

58. Natte, K. et al. Palladium-catalyzed trifluoromethylation of (hetero)arenes with CF3Br. Angew. Chem. Int. Ed. 55, 2782-2786 (2016).

59. Zhang, S. et al. A general and practical Ni-catalyzed C-H perfluoroalkylation of (hetero)arenes. Chem. Commun. 55, 6723-6726 (2019).

60. Ye, F. et al. Versatile fluorinated building blocks by stereoselective (per) fluoroalkenylation of ketones. Eur. J. Org. Chem. 2020, 70-81 (2020).

61. Zhang, S. et al. Selective nickel-catalyzed fluoroalkylations of olefins. Chem. Commun. 56, 15157-15160 (2020).

62. Trost, B. M. New rules of selectivity: allylic alkylations catalyzed by palladium. Acc. Chem. Res. 13, 385-393 (1995).

63. Fujita, T., Sanada, S., Chiba, Y., Sugiyama, K. \& Ichikawa, J. Two-step synthesis of difluoromethyl-substituted 2,3-dihydrobenzoheteroles. Org. Lett. 16, 1398-1401 (2014).

64. Song, H.-X., Han, Q.-Y., Zhao, C.-L. \& Zhang, C.-P. Fluoroalkylation reactions in aqueous media: a review. Green Chem. 20, 1662-1731 (2018).

65. Li, Y., Yang, Y., Xin, J. \& Tang, P. Nucleophilic trifluoromethoxylation of alkyl halides without silver. Nat. Commun. 11, 755 (2020).
66. Mayr, H., Breugst, M. \& Ofial, A. R. Farewell to the HSAB treatment of ambident reactivity. Angew. Chem. Int. Ed. 50, 6470-6505 (2011).

67. Ho, T.-L. The hard soft acids bases (HSAB) principle and organic chemistry. Chem. Rev. 75, 1-20 (1975).

68. Dong, K. et al. Efficient palladium-catalyzed alkoxycarbonylation of bulk industrial olefins using ferrocenyl phosphine ligands. Angew. Chem. Int. Ed. 56, 5267-5271 (2017).

69. Liu, J., Yang, J., Ferretti, F., Jackstell, R. \& Beller, M. Pd-catalyzed selective carbonylation of gem-difluoroalkenes: a practical synthesis of difluoromethylated esters. Angew. Chem. Int. Ed. 58, 4690-4694 (2019).

70. Fanfonia, L., Diaba, L., Smejkal, T. \& Breit, B. Efficient synthesis of new fluorinated building blocks by means of hydroformylation. CHIMIA $\mathbf{6 8}$, 371-377 (2014).

71. Wang, Z.-Y., Wang, Y., Sun, L.-W. \& Zhu, J.-T. Asymmetric synthesis of (R)and (S)-Moprolol. Chem. Res. Chin. Univ. 24, 747-751 (2008).

72. Nakamura, I. \& Yamamoto, Y. Transition-metal-catalyzed reactions in heterocyclic synthesis. Chem. Rev. 104, 2127-2198 (2004).

73. The Njarðarson group. Top 200 Pharmaceuticals by Retail Sales in 2019. https://njardarson.lab.arizona.edu/sites/njardarson.lab.arizona.edu/files/Top\% 20200\%20Drugs\%20By\%20Retail\%20Sales\%20in\%202019V2.pdf (2019).

\section{Acknowledgements}

We are grateful for financial support from the State of Mecklenburg-Western Pomerania and the Federal State of Germany (BMBF). F.Y. and L.-W.X. thank the National Natural Science Foundation of China (Nos. 21773051, 22072035, and 21801056) for financial support. We also thank the Analytic Department (LIKAT) for their kind support.

\section{Author contributions}

M.B. and F.Y. conceived and designed the experiments. F.Y. and Y.G. performed the experiments and analyzed the data. A.S. performed the X-ray analysis. H.N. and L.-W.X participated in the discussions and supported the project. M.B. and F.Y. prepared the manuscript with feedback from all authors.

\section{Funding}

Open Access funding enabled and organized by Projekt DEAL.

\section{Competing interests}

The authors declare no competing interests.

\section{Additional information}

Supplementary information The online version contains supplementary material available at https://doi.org/10.1038/s41467-021-23504-2.

Correspondence and requests for materials should be addressed to M.B.

Peer review information Nature Communications thanks the anonymous reviewer(s) for their contribution to the peer review of this work. Peer reviewer reports are available.

Reprints and permission information is available at http://www.nature.com/reprints

Publisher's note Springer Nature remains neutral with regard to jurisdictional claims in published maps and institutional affiliations.

Open Access This article is licensed under a Creative Commons Attribution 4.0 International License, which permits use, sharing, adaptation, distribution and reproduction in any medium or format, as long as you give appropriate credit to the original author(s) and the source, provide a link to the Creative Commons license, and indicate if changes were made. The images or other third party material in this article are included in the article's Creative Commons license, unless indicated otherwise in a credit line to the material. If material is not included in the article's Creative Commons license and your intended use is not permitted by statutory regulation or exceeds the permitted use, you will need to obtain permission directly from the copyright holder. To view a copy of this license, visit http://creativecommons.org/ licenses/by/4.0/

(C) The Author(s) 2021 